\section{Controle de surto de meningite meningocócica do sorogrupo C no Município de Corupá, Santa Catarina, Brasil, com ações rápidas e efetivas de vigilância epidemiológica e imunização}

\author{
Control of a community outbreak of group C \\ meningococcal meningitis in Corupá, Santa \\ Catarina State, Brazil, based on rapid and effective \\ epidemiological surveillance and immunization
}

Rubens Carlos Bassani Puricelli 1,2 Emil Kupek 2

Rita de Cássia C. Bertoncini 3

\author{
${ }^{1}$ Diretoria de Vigilância \\ Epidemiológica, Secretaria \\ de Estado da Saúde \\ de Santa Catarina, \\ Florianópolis, Brasil. \\ 2 Núcleo de Pesquisas \\ e Estudos em Epidemiologia, \\ Universidade Federal \\ de Santa Catarina, \\ Florianópolis, Brasil. \\ 3 Laboratório Central de \\ Saúde Pública, Secretaria \\ de Estado da Saúde \\ de Santa Catarina, \\ Florianópolis, Brasil. \\ Correspondência \\ R. C. B. Puricelli \\ Diretoria de Vigilância \\ Epidemiológica, Secretaria \\ de Estado da Saúde \\ de Santa Catarina. \\ Rua Rui Barbosa 544, \\ Florianópolis, SC \\ 88025-301, Brasil. \\ puricellirubens@hotmail.com
}

\begin{abstract}
In 2001, an outbreak of eight cases of meningococcal disease within seven days occurred in a small municipality in northern Santa Catarina State, Brazil. All cases occurred in adolescents and young adults, corresponding to an attack rate of 367.5 cases per 100,000 inhabitants in this population group. Laboratory tests identified serogroup $C$ meningococcus in three out of eight cases. This led to vaccination of all inhabitants in the municipality over two years of age against serogroup $C$ meningococcus - an outbreak control strategy recommended by the Brazilian Ministry of Health. The absence of new cases during a 12-month period after vaccination indicates the importance of this type of intervention in disease control.
\end{abstract}

Meningitis; Meningococcus Serogroup C; Disease Outbreaks

\section{Introdução}

A doença meningocócica é uma enfermidade aguda, de prognóstico grave, cujo comportamento, normalmente endêmico, pode também ocorrer sob a forma de epidemia. Nestes casos, obedecidos alguns pré-requisitos, a vacinação, que não faz parte da rotina de imunizações, passa a ser recomendada para a população sob risco 1, devendo ser aplicada em tempo oportuno.

O Estado de Santa Catarina apresentou, no período 1991/2001, taxa de incidência de 7,1 casos de doença/100 mil habitantes/ano, em média. Para os menores de 15 anos de idade, esta incidência foi, em média, de 18,3 casos / 100 mil habitantes, contra 1,8 casos/100 mil habitantes no restante da população. Neste período, $33 \%$ dos casos da doença foram confirmados por meio de métodos que detectam a bactéria ou seus antígenos, e $28 \%$ foram sorogrupados. Destes, $70 \%$ eram do sorogrupo B, e $26 \%$, do sorogrupo C. Nos primeiros cinco anos deste período, a curva de evolução do agravo mostrou-se ascendente, passando de 5,8 casos em 1991 para 11,1 casos/100 mil habitantes em 1995, e o principal responsável por esta ascensão foi o meningococo do sorogrupo C, que passou de $11 \%$ no início do período para $55 \%$ dos casos sorogrupados da doença, em 1995. Para o controle desta situação epidemiológica, foi realizado, no ano de 1996, campanha de vaci- 
nação em massa contra a doença, utilizandose vacina polissacarídea específica. Esta intervenção abrangeu simultaneamente quarenta $\mathrm{e}$ dois municípios do Estado, considerados em situação de epidemia, onde foram vacinados 976.389 crianças e adolescentes na faixa etária de seis meses a quatorze anos de idade, correspondendo a um percentual de cobertura próximo a $100,0 \%$. A efetividade desta intervenção vacinal foi estimada em 93,1\% (IC95\%: 85,2$100,0)$. A partir desta vacinação, a taxa de incidência do agravo passou a apresentar comportamento descendente, reduzindo daqueles 11,1 casos em 1995 para 4,0 casos/ 100 mil habitantes em 2001, e a proporção dos casos de doença meningocócica pelo sorogrupo $\mathrm{C}$ reduziu de $55 \%$, do total de casos sorogrupados naquele ano, para $16 \%$ em 2001 2,3,4.

Nesse cenário, em que a taxa de incidência da doença no Estado já havia declinado para um padrão endêmico, próximo à média brasileira $-3,5$ casos/100 mil habitantes/ano em média, considerando o mesmo período 5 - e em que o meningococo do sorogrupo B predominava com $84 \%$ dos casos sorogrupados, foi diagnosticado importante episódio de surto pela enfermidade em Corupá (Figura 1), Município de 12.014 habitantes, localizado na região Norte de Santa Catarina. Neste Município, foram registrados, no período de 29 de agosto a 4 de setembro de 2001, oito casos confirmados da doença entre adolescentes e adultos jovens, correspondendo a uma taxa de ataque de 367,5 casos/100 mil habitantes deste segmento populacional. Exames laboratoriais identificaram o meningococo do sorogrupo $\mathrm{C}$ em três dos oito casos, o que amparou tecnicamente a utilização, já na semana seguinte ao registro dos primeiros casos da doença, da estratégia do bloqueio vacinal anti-C para o controle do surto ainda restrito àquela comunidade. Os demais municípios que, junto com Corupá, compõem a 17ạ Regional de Saúde, com sede em Jaraguá do Sul, não chegaram a registrar aumento no número de casos da doença naquela oportunidade, apresentando, isoladamente, redução gradativa nas respectivas taxas de incidência do agravo desde 1997. Em seu conjunto, esses municípios registraram declínio dos 9,7 casos / 100 mil habitantes em 1997 para 6,1 casos/100 mil habitantes em 20014.

A efetividade das vacinas constituídas por polissacarídeos dos meningococos dos sorogrupos A e C já foi amplamente documentada pela literatura desde a década de 1970, sendo recomendadas e amplamente utilizadas no controle de epidemias, inclusive no Brasil, onde foram empregadas em amplas campanhas de vacinação em massa 6,7,8. No entanto, a estratégia de vacinação por meio de bloqueio, realizada em Corupá para controlar surto causado pelo meningococo do sorogrupo $\mathrm{C}$, constituiu experiência singular, podendo contribuir para uma maior compreensão sobre os efeitos de uma

Figura 1

Número de casos e taxa de incidência (por 100 mil habitantes) da doença meningocócica.

Corupá, Santa Catarina, Brasil, 1997/2002 (até setembro).

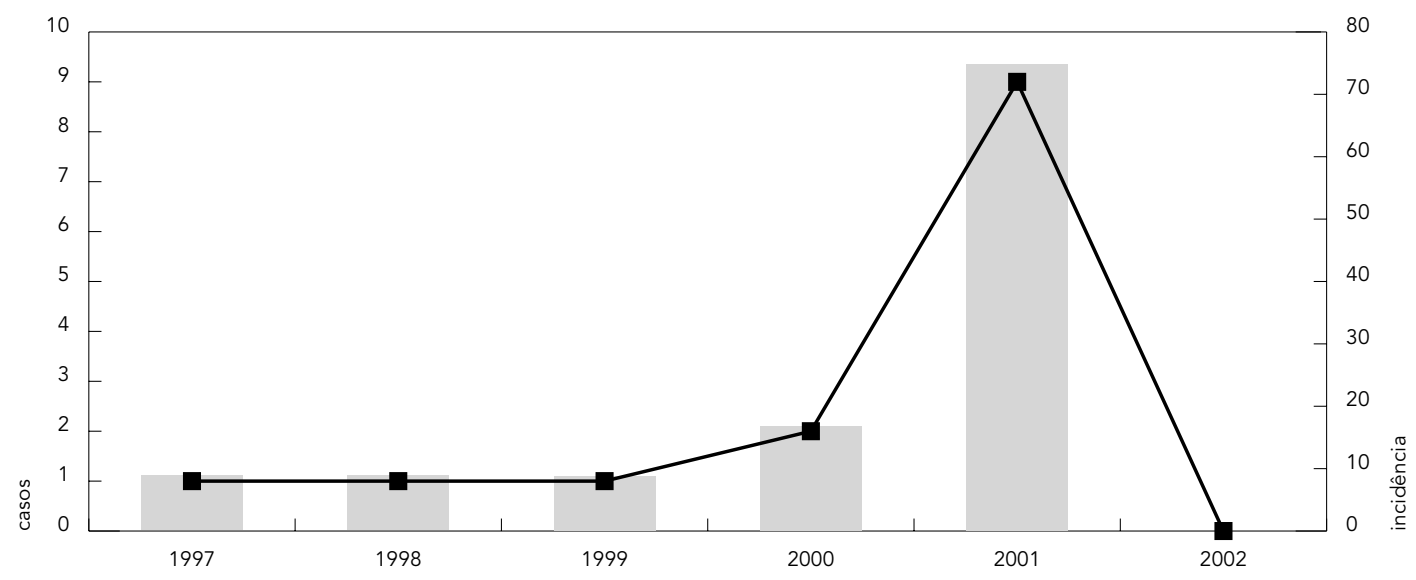

Nota: Em março de 2001 já havia sido registrado um caso da doença. 
rápida intervenção no controle de epidemias pela doença em nosso país.

O objetivo deste artigo é, portanto, descrever as principais características epidemiológicas relacionadas àquele surto, identificando os prováveis elos da cadeia de transmissão da bactéria, e avaliar os efeitos da abordagem vacinal no comportamento epidemiológico da doença meningocócica do sorogrupo C, em Corupá, no período de 12 meses subseqüentes àquela intervenção, ou seja, até 30 de setembro de 2002.

\section{Metodologia}

Os casos suspeitos da enfermidade, todos residentes em Corupá, foram hospitalizados e notificados, de forma imediata, pelo hospital local, ao serviço de vigilância epidemiológica do município. Este deu início ao processo de investigação dos casos preenchendo fichas específicas incluindo, além da identificação dos pacientes, dados clínicos, epidemiológicos e laboratoriais, cuja análise resultou na confirmação do diagnóstico da enfermidade em oito dos dez casos notificados, com base nos seguintes critérios de definição 1: diagnóstico clínico associado à presença de petéquias; bacterioscopia positiva para diplococos Gram negativos; identificação do antígeno específico por meio da aglutinação pelo látex; e cultura do líqüor positiva para Neisseria meningitidis, considerados isolada ou associadamente.

Os dados referentes aos casos registrados da doença na série histórica 1997/2002 foram obtidos no Sistema de Informação de Agravos de Notificação (SINAN), disponíveis na Diretoria de Vigilância Epidemiológica da Secretaria de Estado da Saúde de Santa Catarina. Informações adicionais foram obtidas diretamente das Fichas de Investigação e junto à Secretaria Municipal de Saúde de Corupá.

Dos oito casos confirmados da doença, seis foram internados em hospital de Jaraguá do Sul, um em hospital de Joinville e um em hospital de Mafra. Amostras de líqüor de quatro dos casos, colhidos nos hospitais de Jaraguá do Sul e Joinville, foram depositados em frasco estéril e em meio de cultura ágar chocolate, e enviados para diagnóstico bacteriológico ao Laboratório Central de Saúde Pública (LACEN-SC), em Florianópolis. Os exames laboratoriais das amostras de líqüor dos demais casos foram realizados pelos laboratórios de análises clínicas locais (Jaraguá do Sul e Mafra).

A vacinação de bloqueio realizada em Corupá amparou-se tecnicamente em critérios estabelecidos pelo Ministério da Saúde do Bra- sil (MS) 9, sendo definido como alvo desta intervenção toda a população maior de dois anos de idade, residente no município, estimada em 11.634 habitantes 10. Esta opção decorreu do risco de deslocamento do agravo para outros segmentos da população, caso houvesse restrição ao uso da vacina, do tamanho relativamente pequeno desta comunidade e de sua delimitação no espaço físico ( $80 \%$ dela concentrada na zona urbana). Desta população, 1.157 e 1.020 tinham entre 15 a 19 e 20 a 24 anos de idade respectivamente, e a sua definição como denominador foi decorrente da concentração de casos da enfermidade nestas faixas etárias, constituindo grupo sob maior risco para a doença naquela oportunidade, quando comparado com o restante da população.

O período da vacinação foi previamente estabelecido (de 8 a 11 de setembro/2001), e a vacina utilizada foi a Mencevax AC (Smithkline Beecham), de administração subcutânea, em dose única, aplicada em seis postos fixos e com uma equipe volante. Este imunoprofilático foi fornecido pelo MS, e a liberação da vacina AC, em substituição à monovalente $\mathrm{C}$, foi decorrência de sua disponibilidade. Outras ações, prévias ou paralelas à vacinação, também foram realizadas, como o uso de Rifampicina para quimioprofilaxia dos contatos íntimos, palestras à comunidade em geral, orientação das famílias casa a casa, com distribuição de folders, bem como através dos meios de comunicação (Rádio, TV, Jornais).

\section{Resultados}

Foram registrados em Corupá, no período de 29 de agosto a 4 de setembro de 2001 , oito casos de meningite meningocócica, associada à meningococcemia, entre adolescentes e adultos jovens da faixa etária de 15 a 24 anos de idade, residentes naquele município, o que correspondeu a uma taxa de ataque de 367,5 casos/100 mil habitantes daquele segmento populacional. Um destes casos, com 15 anos de idade, evoluiu para óbito, determinando uma letalidade de 12,5\% (Tabela 1).

Dos oito casos registrados da doença, sete $(87,5 \%)$ acometeram pessoas do sexo masculino, e, em relação à zona de residência, sete moravam nos extremos dos limites urbanos da cidade, e um, na zona rural. Todos os casos eram alunos das Escolas Tereza Ramos (cinco casos), ou Aloísio de Carvalho (dois casos), ambas localizadas na zona urbana, e um caso freqüentava estabelecimento de ensino em Jaraguá do Sul, para onde se deslocava diariamente. Cinco 
Tabela 1

Casos, taxa de ataque (por 100 mil habitantes), óbitos e letalidade pela doença meningocócica. Corupá, Santa Catarina, Brasil, agosto a setembro de 2001.

\begin{tabular}{lcccc}
\hline $\begin{array}{l}\text { Faixa etária } \\
\text { (em anos) }\end{array}$ & Casos & Taxa de ataque & Óbitos & Letalidade (\%) \\
\hline $15-19$ & 5 & 432,2 & 1 & 20,0 \\
$20-24$ & 3 & 294,1 & 0 & 0,0 \\
Total & 8 & 367,5 & 1 & 12,5 \\
\hline
\end{tabular}

Nota: Taxa de ataque por 100 mil habitantes do segmento populacional.

destes estudantes também trabalhavam. Formavam dois grupos distintos, tendo como base a escola onde estudavam, e o quinto caso, na ordem de aparecimento dos primeiros sintomas, sugere ter sido o elo de ligação entre estes dois grupos (Figura 2).

Quatro dias antes do registro do primeiro caso da doença, ocorreu um baile, no qual seis dos oito casos estavam presentes (Figura 2). Consta que as bebidas circulavam entre eles, ingeridas diretamente dos recipientes. Tal comportamento já havia ocorrido na tarde daquele mesmo dia, durante jogo de futebol, do qual participava aquele quinto caso, presente mais tarde ao baile. Outros dois jogadores deste mesmo futebol também vieram a adoecer.

Os principais sintomas apresentados foram: cefaléia, febre e petéquias (nos oito casos ou 100,0\%); vômitos e rigidez de nuca (em sete ou $87,5 \%$ dos casos), dor nos membros inferiores (em cinco ou $62,5 \%$ dos casos) e coma (um caso ou $25,0 \%$ ).

A bactéria $N$. meningitidis sorogrupo $\mathrm{C}$ foi identificada pelo LACEN em três casos, por meio da bacterioscopia + cultura (um caso); cultura + látex (um caso); e citoquímica + aglutinação pelo látex (um caso), correspondendo a $37,5 \%$ do total de casos da doença. A amostra de líqüor do quarto caso não apresentou resultado positivo nos testes bacteriológicos realizados pelo LACEN, e sua definição foi baseada no critério clínico + citoquímica. Os exames laboratoriais dos outros quatro casos foram realizados nos locais de internação, não sendo nenhum deles sorogrupado. Nestes casos, o critério de definição foi: cultura do líquor positivo para N. meningitidis (um caso, ou 12,5\%) e clínico + citoquímica (três casos, ou $37,5 \%$ ). As duas bactérias cultivadas pelo LACEN foram encaminhadas para o Instituto Adolfo Lutz (IAL), em São Paulo, as quais foram identificadas como sendo pertencentes à cepa $C: 4,7$ : P1.19,15.
O primeiro caso da doença (registrado em 29 de agosto) atingiu adolescente de 17 anos de idade. No dia seguinte (30 de agosto), ocorreram três casos (16, 22 e 23 anos de idade). Nos dias 31 de agosto, 2, 3 e 4 de setembro, ocorreram quatro casos $(24,16,15$ e 18 anos de idade, respectivamente). $\mathrm{O}$ acme da epidemia ocorreu, portanto, no dia 30 de agosto e, de acordo com Waldmann 11, retrocedendo-se a partir desta data o tempo equivalente ao período médio de incubação da doença, pode-se chegar ao dia provável da exposição (Figura 3).

No dia oito de setembro, deu-se início ao bloqueio vacinal, e, em três dias, foram vacinadas 12.335 pessoas maiores de dois anos de idade, ultrapassando a meta prevista pelo plano. Em todas as faixas etárias, altos percentuais de cobertura vacinal foram atingidos, inclusive no grupo de 15 a 24 anos de idade, mais suscetível à infecção naquele momento (Figura 4). Nos 12 meses seguintes à intervenção, não foi registrado nenhum caso de doença meningocócica (Figura 1), conferindo à estratégia vacinal, efetividade de $100 \%$

\section{Discussão}

De acordo com Benenson 12 (p. 499), epidemia "é a ocorrência, em uma comunidade ou região, de um conjunto de casos de natureza semelhante, claramente excessiva em relação ao normal esperado". O número de casos da doença registrados em Corupá, no inverno de 2001, foi excepcional, causando pânico na população. Apesar da presença constante do agravo nos quatro anos anteriores a 2001 (Figura 1), a situação epidemiológica da enfermidade no município permanecia endêmica, ocorrendo casos da doença dentro dos limites esperados. Nos anos de 1997 a 1999, os casos registrados acometeram crianças menores de cinco anos de idade. No ano 2000, foram registrados dois casos (3 e 15 anos de idade, do sorogrupo $\mathrm{B}$, não sorotipado) e um caso, em março de 2001, em criança de quatro meses de idade, também pelo sorogrupo B, não sorotipado. Portanto, o diagnóstico laboratorial comprovou a circulação, naquele ambiente, do meningococo do sorogrupo B, situação compatível com o quadro predominante no Estado.

Não são suficientemente conhecidas as razões que possam explicar o aparecimento de uma epidemia. Para que ela ocorra, existe a necessidade da combinação de múltiplos fatores, ligados ao agente etiológico, ao hospedeiro e ao meio ambiente. Isto inclui a susceptibilidade imunológica da população, as condições cli- 


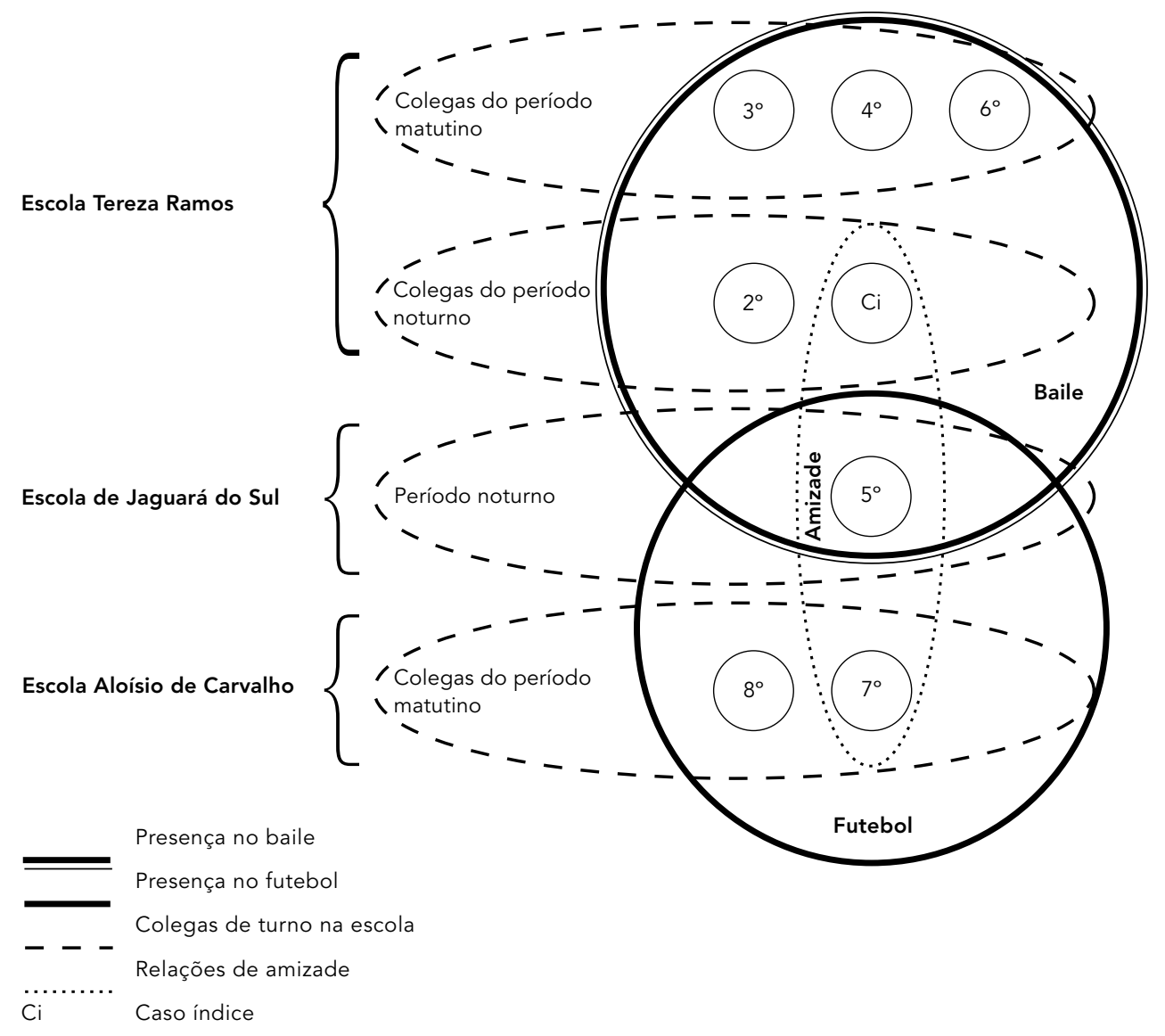

máticas favoráveis, a baixa situação sócio-econômica e a transmissão de cepas virulentas 13,14. Schwartz et al. 13 sugerem que estes fatores são necessários, porém não suficientes para desencadear uma epidemia. Quando estes fatores estão presentes, uma epidemia pode ser iniciada pela presença, por exemplo, de um co-fator infeccioso, representado por infecções agudas do trato respiratório, que podem comprometer as mucosas e aumentar a probabilidade de invasão pela bactéria. Aglomerações em discotecas e eventos esportivos, hábito de fumar, alcoolismo, fadiga e estresse por acúmulo ou excesso de trabalho, entre outros, são também relacionados como fatores de risco para a doença invasiva $15,16,17,18$.

No Estado de Santa Catarina, observam-se casos da doença durante todos os meses do ano. No inverno, porém, estação que atinge o
Estado nos meses de julho a setembro, ocorrem aumento no número de casos (estatisticamente significante - IC95\%) e óbitos pela enfermidade 2 , como decorrência da maior possibilidade de transmissão do meningococo pela aglomeração das pessoas, devido ao frio, em ambientes fechados 16,19,20. Iversson 16 relata que, nesses períodos de baixas temperaturas, são também mais freqüentes as afecções do trato respiratório, que contribuem para a disseminação das bactérias da nasofaringe.

O risco da doença meningocócica difere entre os sorogrupos, e certas cepas do meningococo são mais virulentas que outras, estando mais associadas à presença de epidemias 14 . Por outro lado, a imunidade humoral da população é um fator essencial na prevenção da doença meningocócica e seu declínio em relação a uma determinada cepa em particular pode ser o fa- 
Figura 3

Casos de doença meningocócica distribuídos segundo a data do início dos sintomas.

Corupá, Santa Catarina, Brasil, agosto a setembro de 2001.



Figura 4

Número de pessoas vacinadas por faixa etária e o percentual de cobertura vacinal. Corupá, Santa Catarina, Brasil, setembro de 2001.

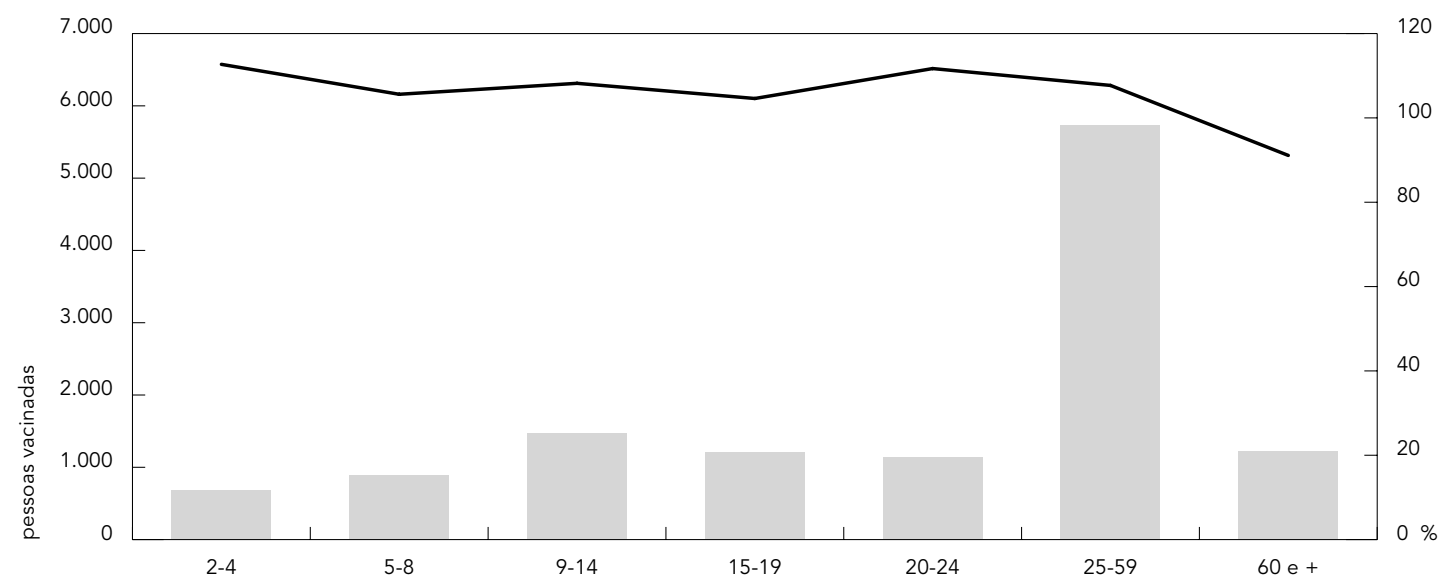

Nota: Os altos percentuais de cobertura vacinal decorreram do afluxo de residentes em municípios limítrofes. 
tor necessário para a ocorrência de um surto 14,21. Estudos sugerem também que pode ocorrer, dependendo da proporção de portadores do meningococo numa comunidade, mudança na cápsula do meningococo, o que lhe permite defender-se dos anticorpos anticapsulares preexistentes, podendo resultar em importante mecanismo de virulência da bactéria 19,22. Não se afasta, portanto, a possibilidade de que possa ter havido, em Corupá, mudança da cepa B:4,7: P1.19,15, comum em Santa Catarina $56,7 \%$ dos casos sorotipados pelo IAL em 20014 - para a cepa C:4,7:P1.19,15, esta até então não identificada no Estado 23.

Em situações endêmicas, os grupos populacionais de maior risco para a doença são os menores de cinco anos de idade, e este risco passa a ser menor na medida em que avança a idade 13,14. Essa relação entre risco e idade pode ser observada também em Santa Catarina, cujas taxas de incidência pela doença, no período 1991/2001, foram em média de 38,7 casos/100 mil habitantes para a população menor de 5 anos de idade; de 9,4 para o grupo de 5 a 14; de 5,6 para o grupo de 15 a 19; de 1,7 para o grupo de 20 a 24; de 1,4 para o grupo de 25 a 49 e de 0,8 casos $/ 100$ mil habitantes para o grupo de 50 ou mais anos de idade, em média 4.

Em situações de epidemia, é comum a mudança na faixa etária, passando a doença a incidir mais intensamente em outros segmentos da população, o que constitui uma das características de epidemia pelo meningococo ${ }^{19}$. Em Corupá, o episódio epidêmico coincidiu com a estação mais fria do ano, atingindo segmento populacional normalmente menos susceptível à infecção, quando comparado com outros grupos de menor idade. Entre os adolescentes, os vínculos sociais são normalmente mais intensos, contribuindo para uma maior aproximação entre as pessoas. Entretanto, a simples exposição a um portador, facilitada pelo convívio mais estreito, não significa necessariamente, de acordo com Schwartz et al. 13, a transmissão da bactéria, bem como sua eventual transmissão não determina obrigatoriamente o aparecimento da doença. No entanto, aquele intervalo de dias entre baile/futebol e o pico da epidemia (Figura 3) é compatível com o período médio de incubação da doença 1 , sugerindo que estes eventos sociais podem estar associados à exposição e às possíveis formas de disseminação da bactéria.

Constatada uma situação de epidemia pela doença, o uso de vacinas antimeningocócicas passa a ser recomendado para proteção da população, apesar de suas limitações tanto em relação à faixa etária em que conferem proteção, como ao tempo de duração da proteção conferida 1,24 . No que se refere especificamente à vacina contra o meningococo do sorogrupo C, a mesma adquire maior potência imunogênica quando aplicada em crianças a partir de dois anos de idade, e deve ser administrada a todas as pessoas, com exceção das crianças de tenra idade, no caso de epidemia pela doença meningocócica deste sorogrupo 8. Para o Centers of Disease Control and Prevention 7, dos Estados Unidos, estas vacinas demonstram eficácia clínica estimada de 85 a $100 \%$ em crianças mais velhas e adultos, recomendando a sua utilização no controle de epidemias pela enfermidade.

De acordo com Hubert \& Caugant 25, o aumento de infecções pelo meningococo do sorogrupo C, observado em alguns países, tem despertado o interesse pelas campanhas de vacinação, e vários critérios têm sido utilizados para decidir sobre sua implementação. Estados Unidos e Canadá, bem como alguns países europeus, registraram, na década de 1990, aumento de surtos causados pelo meningococo $\mathrm{C}$, em instituições e pequenas comunidades, que atingiram, de forma desproporcional, crianças em idade escolar e adultos jovens, o que levou a um considerável aumento na utilização das vacinas anti-C para o seu controle 26,27. No entanto, para ser efetiva, a vacinação deve ser instituída em tempo oportuno no curso da epidemia 27,28.

Em Santa Catarina, haviam sido realizadas, até então, três amplas campanhas de vacinação em massa para combater a epidemia pela doença meningocócica (1975, 1990 e 1996), o que ocorreu após sua expansão para diversos municípios, atingindo parcela significativa da população catarinense. A análise da curva de evolução do agravo em relação às datas de intervenção vacinal sugere, no entanto, que o uso do imunoprofilático poderia ter sido antecipado, desde que as condições para esta decisão estivessem presentes no momento oportuno. Assim, nos três anos anteriores à vacinação de 1975, as taxas de incidência da doença haviam evoluído dos 1,8 casos, registrados em 1972, para 6,1 casos em 1973 e 26,1 casos/ 100 mil habitantes em 1974, só ocorrendo intervenção no ano seguinte. Da mesma forma, nos anos anteriores à segunda campanha de 1990, as taxas de incidência da doença, que já vinham em ascensão desde 1983, atingiram a 8,6 casos em 1988 e a 9,7 casos/100 mil habitantes em 1989. Quanto à última campanha, as taxas haviam evoluído dos já altos 8,1 casos, em 1993, para 9,1 em 1994 e 11,1 casos/100 mil habitantes em 1995, e as ações de controle só foram desencadeadas no ano de 19962. 
Essa tendência de intervenções tardias tem precedentes na literatura brasileira. A inexistência de um adequado sistema de vigilância epidemiológica, a falta de dados confiáveis, a ausência de laboratórios de saúde pública, ou a negação pura e simples da epidemia pela doença foram fatores apontados para justificar o atraso no reconhecimento da verdadeira situação epidemiológica que atingiu o país e o conseqüente uso da vacinação na década de 1970 29,30. Para combater esta epidemia, que chegou a registrar, em algumas cidades, incidência de 170 casos/100 mil habitantes, foi desencadeada campanha de vacinação em massa contra a enfermidade em abril de 1975 , somente após o início do declínio da incidência (Rodrigues \& Alves Filho, 1989, apud Amato Neto et al. 8).

O evento vacinal em Corupá, por sua vez, foi iniciado já na semana seguinte ao registro dos primeiros casos da doença, e, no período de doze meses após o bloqueio vacinal, não foi registrado nenhum caso da enfermidade no município. Mesmo considerando que outros fatores possam estar relacionados àquela redução, o declínio observado sugere ser decorren- te dos efeitos daquela estratégia vacinal, e seus resultados, compatíveis com os registros da literatura $31,32,33$.

A detecção precoce de eventuais surtos da enfermidade, possível quando os casos são imediatamente notificados, permite empregar os atuais conhecimentos sobre o uso potencial das vacinas antimeningocócicas prontamente, beneficiando a população sob risco. A partir do ano de 2000, com a adoção, pelo MS 9, de critérios para a vacinação de bloqueio, recomendados pela Comissão Nacional das Meningites, a habilitação ao uso destas vacinas passou a ser facilitada, contribuindo para pronta intervenção.

$\mathrm{O}$ bloqueio vacinal relatado neste artigo, realizado em tempo hábil no curso da evolução da doença, fornece sólidos argumentos a favor de sua contribuição para a interrupção do processo epidêmico, limitando as possibilidades de sua expansão para outras áreas e reduzindo, com isso, os riscos de morbi-mortalidade pela enfermidade. Portanto, a estratégia de bloqueio vacinal realizado em Corupá sugere ser método útil para o controle de surtos pelo meningococo do sorogrupo C.

\section{Resumo}

No ano de 2001, num período de sete dias, em município de pequeno porte localizado na região norte de Santa Catarina, Brasil, foram registrados oito casos de doença meningocócica entre adolescentes e adultos jovens, correspondendo a uma taxa de ataque de 367,5 casos/100 mil habitantes deste segmento populacional. Exames laboratoriais identificaram o meningococo do sorogrupo C em três dos oito casos, o que permitiu utilizar, de acordo com os critérios estabelecidos pelo Ministério da Saúde do Brasil, a estratégia do bloqueio vacinal anti-C para o controle do agravo naquela população sob risco. A vacinação foi levada a todas as pessoas maiores de dois anos de idade, residentes no município. A ausência de casos da doença meningocócica naquela comunidade nos 12 meses após o bloqueio vacinal sinaliza para a importância da pronta intervenção no controle de surtos pela enfermidade.

Meningite; Meningococcus Sorogrupo C; Surtos de Doenças

\section{Colaboradores}

R. C. B. Puricelli coordenou os trabalhos, participou do levantamento dos dados e da redação do texto. E. Kupek participou na elaboração do texto e prestou assessoria na metodologia adotada. R. C. S. Bertoncini participou na elaboração do texto, no levantamento bibliográfico e no levantamento dos dados laboratoriais. 


\section{Referências}

1. Ministério da Saúde. Guia de vigilância epidemiológica. Brasília: Fundação Nacional de Saúde; 2002.

2. Puricelli RCB. A doença meningocócica no Estado de Santa Catarina, no período 1994-1998 [Dissertação de Mestrado]. Florianópolis: Universidade Federal de Santa Catarina; 2000.

3. Kupek E, Puricelli RCB, Westrupp MHB. Effectiveness of a mass immunization campaign against serogroup $\mathrm{C}$ meningococci in children in the Federal State of Santa Catarina, Brazil. Braz J Infect Dis 2001; 5:324-31.

4. Secretaria de Estado da Saúde de Santa Catarina. Relatórios técnicos - meningites. Florianópolis: Diretoria de Vigilância Epidemiológica, Secretaria de Estado da Saúde de Santa Catarina; 2002.

5. Ministério da Saúde. Situação das meningites no Brasil. Brasília: Fundação Nacional de Saúde; 2003.

6. Artenstein MS, Gold R, Zimmerly JG, Wyle FA, Schneider H, Harkins C. Prevention of meningococcal disease by group $\mathrm{C}$ polissacharide vaccine. N Eng J Med 1970; 282:417-20.

7. Centers for Disease Control and Prevention. Control and prevention of meningococcal disease: recommendations of the advisory committee on immunization practices. MMWR Morb Mortal Wkly Rep 1997; 46:1-51.

8. Amato Neto V, Baldy JLS, Silva LJ. Imunizações. São Paulo: Editora Sarvier; 1991.

9. Ministério da Saúde. Critérios para utilização de vacinas em meningites. Brasília: Coordenação de Vigilância das Doenças de Transmissão Respiratória, Centro Nacional de Epidemiologia, Fundação Nacional de Saúde; 2000.

10. Fundação Instituto Brasileiro de Geografia e Estatística. População residente - Santa Catarina. http// www.saude.sc.gov.br (acessado em 06/Jul/2002).

11. Waldmann EA. Vigilância em saúde pública. São Paulo: Fundação Peirópolis; 1998.

12. Benenson AS. Control of communicable diseases in man. Washington DC: American Public Health Association; 1990.

13. Schwartz B, Moore PS, Broome CV. Global epidemiology of meningococcal disease. Clin Microbiol Rev 1989; 2 Suppl:S118-24.

14. World Health Organization. Control of epidemic meningococcal disease. Geneva: World Health Organization; 1998.

15. Young LS, Laforce FM, Head JJ, Feeley JC, Bennett JV. A simultaneous outbreak of meningococcal and influenzae infections. N Engl J Med 1972; 287:5-9.

16. Iversson LB. Aspectos epidemiológicos da meningite meningocócica no Município de São Paulo (Brasil), no período de 1968-1974. Rev Saúde Pública 1976; 10:1-16.

17. Davies AL, O'Flanagan D, Salmon RL, Coleman TJ. Risk factors for Neisseria meningitidis cariage in a school during a community outbreak of meningococcal infection. Epidemiol Infect 1996; 117:259-66.

18. Imrey PB, Jackson LA, Ludwinski PH. Meningococcal carriage, alcohol consumption and campus bar patronage in a serogroup $\mathrm{C}$ meningococcal disease outbreak. J Clin Microbiol 1995; 33: 3133-7.
19. Whalen CM, Hockin JC, Ryan A, Fraser A. The changing epidemiology of invasive meningococcal diseases in Canada, 1985 through 1992. JAMA 1995; 273:645-51.

20. Pinner RW, Gellin BG, Bibb WF, Baker CN, Weaver $\mathrm{R}$, Hunter SB, et al. Meningococcal diseases in the United States - 1986. J Infect Dis 1991; 164:36874.

21. Moore PS. Meningococcal meningitis in Sub-Sahara Africa: a model for the epidemic process. Clin Infect Dis 1992; 11:515-5.

22. Swartley JS, Marfin AA, Edupuganti S, Liu LJ, Cieslak P, Perkins B, et al. Capsule switching of Neisseria meningitidis. Proc Natl Acad Sci U S A 1997; 94:271-6.

23. Bertoncini RCC. Estudo epidemiológico das cepas de Neisseria meningitidis isoladas de casos de doença meningocócica em Santa Catarina 1987 a 1998 [Dissertação de Mestrado]. São Paulo: Faculdade de Saúde Pública, Universidade de São Paulo; 2001.

24. Costa WA. Vacinas contra a doença meningocócica. J Pediatr (Rio J) 1995; 71:62-6.

25. Hubert B, Caugant DA. Evolução recente das infecções meningocócicas na Europa. Euro Surveill $1997 ; 2: 33-4$.

26. Ashton FE, Ryan JA, Borczyk AL, Caugant DA, Mancino L, Huang D. Emergence of a virulent clone of Neisseria menigitidis serotype $2 \mathrm{a}$ that is associated with meningococcal group $\mathrm{C}$ disease in Canada. J Clin Microbiol 1991; 29:2489-93.

27. Jackson LA, Schuchat A, Reeeves MW, Wenger JD. Serogroup C meningococcal outbreaks in the United States. An emerging threat. JAMA 1995; 273:383-9.

28. Pinner RW, Onyango F, Perkins BA, Mirza NB, Ngacha DM, Reeves M, et al. Epidemic meningococcal disease in Nairobi, Kenya, 1989. J Infect Dis 1992; 166:359-64.

29. Oliveira NM. Campanha de vacinação contra a meningite meningocócica - contribuição a seu estudo [Tese de Doutorado]. Ribeirão Preto: Faculdade de Medicina, Universidade de São Paulo; 1985.

30. Barata RCB. Meningite: uma doença sob censura? São Paulo: Cortez; 1988.

31. Pearce MC, Sheridan JW, Jones DM, Lawrence GW, Murphy DM, Masutti B, et al. Control of group $\mathrm{C}$ meningococcal disease in Australian Aboriginal children by mass refampicin chemoprophylaxis and vaccination. Lancet $1995 ; 346: 20-3$.

32. De Wals P, Dionne M, Douville-Fradet M, Boulianne N, Drapeau J, De Serres G. Impact of a mass immunization campaign against serogroup $C$ meningococus in the Province of Quebec, Canada. Bull World Health Organ 1996; 74:407-11.

33. Rosenstein N, Levine O, Taylor JP, Evans D, Plikaytis $\mathrm{BD}$, Wenger JD, et al. Efficacy of meningococcal vaccine and barriers to vaccination. JAMA 1998; 279:435-9.

Recebido em 26/Mar/2003

Versão final reapresentada em 23/Dez/2003

Aprovado em 30/Jan/2004 